\title{
Research article \\ A comparative evaluation of mikrolatest kit broth microdilution and VITEK2 in assessing colistin susceptibility to Gram-negative bacterial isolates
}

\author{
B. Rama Chandra Reddy ${ }^{1}$, PAT Jagatheeswary ${ }^{2}$, Manisha Singh $^{3}$, Y. Raja Ratna Reddy ${ }^{4}$, K. Sreeja Vamsi ${ }^{1}$, Nissi \\ Priya $^{1}$
}
${ }^{1}$ Assistant Professor, ${ }^{4}$ Associate Professor, Department of Microbiology, S.V.S Medical College, Mahaboobnagar, Telangana, India
${ }^{2}$ Professor, Department of Microbiology, Saveetha Medical College, Saveetha University, Chennai, Tamil Nadu, India
${ }^{3} \mathrm{Head}$, Department of Microbiology, Vijaya Diagnostic Centre, Himayathnagar, Hyderabad, Telangana, India

(Received: August $2020 \quad$ Revised: March $2021 \quad$ Accepted: April 2021)

Corresponding author: PAT Jagatheeswary. Email: patjags@ rediffimail.com

\begin{abstract}
Introduction and Aim: The increasing resistance in colistin is a major concern. The aim of the study was to compare the methods to identify the prevalence of colistin resistance and antibiotic susceptibility patterns of colistin resistant strains isolates from blood, urine and sputum samples at all ICUs including NICU and PICU and wards.

Materials and Methods: A total of 1458 consecutive Gram-negative isolates were tested for colistin susceptibility by standard broth microdilution method, Mikrolatest method and VITEK 2 automation system. Intrinsically colistin resistant organisms including Proteus sps, Providencia sps, Serratia sps., and Morganella morganii were excluded. Enterobacteriaceae (e.g., Escherichia coli, Klebsiella), Pseudomonas aeruginosa and Acinetobacter baumanii were included. The sensitivity, specificity, positive predictive value, negative predictive value of Vitek-2, BMD and Mikrolatest methods were compared.
\end{abstract}

Results: Sixteen $(1.09 \%)$ colistin-resistant isolates were reported over 24 months. K. pneumoniae constituted 8(50\%), E. coli $6(37.5 \%)$ and Enterobacter cloacae $2(12.5 \%)$ of the 16 resistant isolates. The sensitivity, specificity, positive predictive value, negative predictive value of Mikrolatest compared with that of VITEK2 were $87.5 \%$ vs $56.25 \%, 90.84 \%$ vs $82.65 \%, 9.58 \%$ vs $3.47 \%$ and $99.8 \%$ vs $99.3 \%$, respectively for resistant isolates. Mikrolatest shared good Category agreement of $1.24 \%$ with BMD Essential agreement was $1.5 \%$. Comparing MICs of BMD with other tests, essential agreement was the lowest for the VITEK2, while the Mikrolatest MIC showed essential agreement greater than $1.5 \%$. No errors and $100 \%$ categorical agreement (for E. coli, K. pneumoniae) were observed while comparing colistin susceptibility test results of the Mikrolatest MIC and BMD tests. The difference between the two methods in assessing colistin resistance were not statistically significant $(\mathrm{P}=0.89)$. Blood[37.5\%] and pus[37.5\%] samples recorded as the common sources of the isolate, followed by Urine [12.5\%], and respiratory [12.5\%) samples.

Conclusion: Automated VITEK, Mikrolatest MIC methods give variable susceptibility results and colistin should be prescribed only after Mikrolatest and BMD. K. pneumoniae and E. coli, the Mikrolatest showed better performance for isolates with $\leq 0.5$ or $\geq 16 \mu \mathrm{g} / \mathrm{mL}$ MICs. For $P$. aeruginosa isolates, colistin resistant isolates must be confirmed Colistin resistance among Gram-negative bacteria, especially $K$. pneumoniae, is emerging in Indian hospitals. Re-evaluation is required of the methods available to address the numerous technical challenges associated with colistin susceptibility testing, and to determine which method yields the most meaningful results. These studies will provide critical information on the appropriate selection of colistin therapy, as well as evaluating novel and upcoming compounds with structure and properties similar to the Polymyxin.

Keywords: Gram-negative bacilli; colistin resistance; Mikrolatest; broth micro-dilution method.

\section{INTRODUCTION}

I $\mathrm{CU}$ patients are highly susceptible to nosocomial infections due to severity of disease, prolonged hospital stay, immunosuppression, prolonged usage of indwelling medical devices such as central line catheters, mechanical ventilators, nasogastric tubes, foley's urine catheters and other comorbidities. The higher use of broad-spectrum and/or multiple antibiotics in the ICUs is associated with a higher rate of emergence of the resistant Gram-negative bacteria $(1,2)$. Over the last two decades, only two new classes of antibiotics have been introduced into the pharmaceutical markets (linezolid and oxazolidinones); none of these antibiotics are significantly active against the Gram-negative bacteria $(3,4)$.

Carbapenems are broad- spectrum antimicrobial agents that are very useful against infections caused by MDR Enterobacteriaceae (5) and are drugs of choice against infections caused by extendedspectrum beta-lactamase (ESBL)-producing Gramnegative bacteria (6). Gram-negative bacteria have 
developed various resistance mechanisms such as the production of carbapenemase enzymes including $\beta$ lactamases (NDM, IMP, VIM, OXA, KPC, SIM $(7,8)$. The emergence of resistant bacteria against various antibiotics and shortage of newly discovered antibiotics had led to the usage of polymyxins as valuable treatment option (9).

Polymyxin E (colistin) discovered in 1947 is a member of the Polymyxin group polypeptide antibiotics with a significant activity against Gramnegative bacteria and it targets lipopolysaccharide in the outer membrane by strong positive charge and a hydrophobic acyl chain $(10,11)$. These drugs shown in vitro multidrug-resistant (MDR)activity against the Gram-negative bacteria which include Pseudomonas aeruginosa, Klebsiella pneumoniae, Acinetobacter baumannii, Stenotrophomonas maltophilia. Pseudomonas aeruginosa and Acinetobacter baumannii with MICs of $\leq 4$ and $\leq 2 \mathrm{mg} / \mathrm{L}$ colistin sulphate, respectively $(12,13)$. Due to nephrotoxicity and neurotoxicity the usage of colistin was abandoned at early 1980s.

There have been limited current national surveillance studies to evaluate in vitro activity of colistin versus Gram-negative bacterial isolates. Hence, the the current study was aimed to evaluate the in vitro activity of colistin against Gram-negative bacilli obtained from patients in ICUs including PICU and NICU in the current setting.

Antimicrobial susceptibility tests were performed using commercially available automated systems, which included the VITEK2 (bioMérieux) and MicroScan (Siemens) systems. Broth microdilution (BMD) is a well-established, standard method, but it is labor-intensive for clinical laboratories. Antimicrobial susceptibility testing for Ertapenem can be performed by using all the above techniques; but, most of the laboratories lack the experience and very little data regarding comparing the efficacies of the different techniques (14-16).

This study investigated different antimicrobial susceptibility testing methods, including the VITEK2, BMD, and Mikrolatest MIC tests, to detect colistin resistance in isolates from a clinical microbiology laboratory at a tertiary care hospital. The study evaluated the percentage of categorical agreement between these test methods.

\section{MATERIALS AND METHODS}

This cross-sectional study was conducted in intensive care units including PICU, NICU, OBGY and other wards of SVS Medical College and Hospital, Mahabubnagar during August 2018 to July 2020. The institutional ethics committee approved the study protocol. This study was carried out on 1458 Gramnegative bacilli isolated from the bacterial samples obtained from different organs of patients (ICUs). The isolates were collected from clinical microbiology laboratory of our tertiary hospital, all of which were detected colistin resistance by the VITEK 2 combat system, BMD and Mikrolatest MIC tests.

\section{Inclusion criteria}

ICU cases with more than 48 hours of hospitalization.

Patients of all age groups (including pediatrics) were included. Enterobacteriaceae (e.g., Escherichia coli, Klebsiella), Pseudomonas aeruginosa and Acinetobacter baumanii were included.

\section{Exclusion criteria}

Intrinsically colistin resistant organism including Proteus sps, Providencia sps, Serratia sps and Morganella morgani were excluded. Patients who were not willing to give the consent.

\section{Bacterial isolates}

All the kits and reagents used for this study were prepared according to the manufacturer's recommendations and guidelines. A total of 1458 consecutive Gram-negative isolates were tested for Colistin susceptibility by Vitek 2 AST- N281 cards (Biomerieux, Marcy L'Etoile, France), BMD and using Mikrolatest MIC Colistin kit.

\section{Susceptibility testing}

The specimens were processed by standard method, bacteria identified and tested. Antimicrobial susceptibility for Colistin was analysed by using the VITEK2 using AST card (bioMérieux), according to the manufacturer's instructions with compact automation system, intrinsically colistin resistant organism including Proteus sps., Providencia sps., Serratia sps., and Morganella morgani were excluded. Enterobacteriaceae (e.g., Escherichia coli, Klebsiella), Pseudomonas aeruginosa and Acinetobacter baumanii included. Colonies from an overnight agar plate culture of each isolate were suspended in $3 \mathrm{~mL}$ of $0.45 \%$ saline and adjusted to a turbidity of 0.5 McFarland standard with VITEK Densicheck (bioMérieux).

All Colistin resistant strains were further processed. The minimum inhibitory concentration (MIC) of antibiotics was determined by the broth microdilution method. Interpretation was performed according to the EUCAST breakpoints (www.eucast.org).

\section{Test for detection of Minimum inhibitory concentration-(MIC) of Colistin}

Broth microdilution is considered the reference standard for Polymyxin susceptibility testing. Escherichia coli ATCC 25922 was used as a negative control. For preparation of antibiotic stock solution, Colistin drug in powder form (commercial source with given potency) and stored at $4^{0} \mathrm{C}$ until use. 
Antibiotic stock solution was prepared based on the requirements.

The inoculum was prepared by direct broth suspension of isolated colonies selected from $24 \mathrm{hr}$ blood agar plate. The suspension was adjusted to attain turbidity of 0.5 (McFarland turbidity standard).

96-well microtitre plates filled with Mueller Hinton II broth (CAMHB, Himedia labs), serial two -fold diluted concentration of antimicrobial agents and McFarland standard tested bacteria was added. The plates were incubated at $35^{\circ} \mathrm{C}$ for $24-48 \mathrm{hrs}$. The bacterial growth was arrested, and the turbidity was measured.

Minimum inhibitory concentration precise method of susceptibility testing allows quantification of the exact concentration $(\mu \mathrm{g} / \mathrm{ml})$ of the antibiotic needed to inhibit the bacterial growth. The BMD MIC test range was $0.25 \mu \mathrm{g} / \mathrm{mL}$ to $128 \mu \mathrm{g} / \mathrm{mL}$. The results of BMD were considered the reference standard against which all other results were compared.

\section{MIKROLATEST \\ Minimum \\ Concentration (MIC) \\ Inhibitory}

This is based on the broth microdilution method to quantify in vitro activity of antimicrobial agents. The MIC is determined from $2 \mathrm{X}$ dilution (7 concentrations) as the lowest concentration of an antimicrobial agent which prevents visible growth of bacteria. The MIC of Colistin was determined by using MIKROLATEST® MIC Colistin kit (Erba Lachema). Test was done as per kit literature. Results were interpreted by visual reading of plate. The reference strain E. coli ATCC 25922 was also included in the study as a control.

It is a broth micro dilution test which is CE=IVD approved for testing for Colistin. The cut offs provide are $0.25,0.5,1.0,2.0,4.0,8.0$ and $16.0 \mathrm{mcg} / \mathrm{ml}$.

\section{Statistical analysis}

Table 1. Details of MIC values by different methods

\begin{tabular}{|c|c|c|c|}
\hline Isolates (total 16) & MIC by Vitek & MIC by BMD & MIKROLA TEST MIC \\
\hline E.coli- Bronchoalveolar lavage fluid & $>=16$ & $16 \mu \mathrm{g} / \mathrm{ml}$ & $16 \mu \mathrm{g} / \mathrm{ml}$ \\
\hline E.coli-Pus & 8 & $8 \mu \mathrm{g} / \mathrm{ml}$ & $8 \mu \mathrm{g} / \mathrm{ml}$ \\
\hline E.coli- Pus & $\geq 16$ & $16 \mu \mathrm{g} / \mathrm{ml}$ & $16 \mu \mathrm{g} / \mathrm{ml}$ \\
\hline Klebsiella-Blood & 0.5 & $16 \mu \mathrm{g} / \mathrm{ml}$ & $16 \mu \mathrm{g} / \mathrm{ml}$ \\
\hline Klebsiella-Blood & 2 & $4 \mu \mathrm{g} / \mathrm{ml}$ & $4 \mu \mathrm{g} / \mathrm{ml}$ \\
\hline Klebsiella-Blood & 8 & $4 \mu \mathrm{g} / \mathrm{ml}$ & $16 \mu \mathrm{g} / \mathrm{ml}$ \\
\hline Klebsiella-Pus & $\geq 16$ & $16 \mu \mathrm{g} / \mathrm{ml}$ & $16 \mu \mathrm{g} / \mathrm{ml}$ \\
\hline Enterobacter cloacae-Urine & 8 & $16 \mu \mathrm{g} / \mathrm{ml}$ & $16 \mu \mathrm{g} / \mathrm{ml}$ \\
\hline E.coli-Pus & 4 & $8 \mu \mathrm{g} / \mathrm{ml}$ & $4 \mu \mathrm{g} / \mathrm{ml}$ \\
\hline E.coli-Pus & 4 & $16 \mu \mathrm{g} / \mathrm{ml}$ & $8 \mu \mathrm{g} / \mathrm{ml}$ \\
\hline E.coli-Urine & 8 & $16 \mu \mathrm{g} / \mathrm{ml}$ & $8 \mu \mathrm{g} / \mathrm{ml}$ \\
\hline Klebsiella-Pus & 8 & $16 \mu \mathrm{g} / \mathrm{ml}$ & $16 \mu \mathrm{g} / \mathrm{ml}$ \\
\hline Klebsiella-Blood & 4 & $8 \mu \mathrm{g} / \mathrm{ml}$ & $8 \mu \mathrm{g} / \mathrm{ml}$ \\
\hline Klebsiella-Blood & 16 & $8 \mu \mathrm{g} / \mathrm{ml}$ & $16 \mu \mathrm{g} / \mathrm{ml}$ \\
\hline Klebsiella-Blood & 0.5 & $8 \mu \mathrm{g} / \mathrm{ml}$ & $8 \mu \mathrm{g} / \mathrm{ml}$ \\
\hline Enterobacter cloacae- & 8 & $4 \mu \mathrm{g} / \mathrm{ml}$ & $8 \mu \mathrm{g} / \mathrm{ml}$ \\
\hline Bronnl & & \\
\hline
\end{tabular}

The chi square test was done to assess the relationship between the qualitative variables. The results of different antimicrobial susceptibility testing methods were compared to those of BMD. Categorical variables were presented as proportions while continuous variables were presented as mean with standard deviation (SD). The chi square test was done to assess the relationship between the qualitative variables. Sensitivity, specificity, and positive and negative predictive values (PPV and NPV, respectively) of each method for the detection of colistin resistance were calculated to evaluate performance. p-value $<0.05$ was considered statistically significant. All statistical tests were performed using SPSS version 24 software (SPSS Inc, Chicago, IL, USA).

\section{RESULTS}

The resistant rates (\%) to colistin as determined by the Vitek, MIKROLATEST MIC and BMD tests.

\section{Bacterial isolates}

We studied a total of 1458 isolates of the Gramnegative bacteria during from 2018 August to July 2019. Sixteen $(1.09 \%)$ colistin-resistant isolates were reported over 12 months.

Results of colistin susceptibility test using VITEK, BMD and Mikrolatest MIC antibiotic susceptibility testing kit, respectively, of all 16 bacterial isolates along with those of control strains are shown in [Table 1]. Colistin susceptibility of E. coli (MIC: 8$16 \mu \mathrm{g} / \mathrm{ml}$ ) and Klebsiella (MIC: $4-16 \mu \mathrm{g} / \mathrm{ml}$ ) was ascertained (Table 1). Acinetobacter spp. and $P$. aeruginosa test isolates were classified as colistin susceptible (MIC $\leq 2 \mu \mathrm{g} / \mathrm{ml}$ ) or resistant (MIC $>4$ $\mu \mathrm{g} / \mathrm{ml}$ ) respectively as per CLSI 2019 guidelines [Table 2]. Colistin susceptibility of $E$. coli and $K$. pneumoniae test isolates (MIC $\leq 2$ [sensitive] and $>2$ $\mu \mathrm{g} / \mathrm{ml}$ [resistant]). 
Table 2: The MIC was determined by broth dilution method following the Clinical and Laboratory Standards Institute (CLSI) guideline

\begin{tabular}{|c|c|c|c|c|}
\hline & \multicolumn{2}{|c|}{ EUCAST } & \multicolumn{2}{c|}{ CLSI } \\
\hline & Susceptible & Resistant & Susceptible & Resistant \\
\hline Enterobacteriaceae & $<=2$ & $>=4$ & & \\
\hline $\begin{array}{c}\text { Pseudomonas } \mathrm{spp} \\
(\text { P. aeruginos } \mathrm{clsi})\end{array}$ & $<=2$ & $>=4$ & $<=2$ & $>=4$ \\
\hline Acinetobacter $\mathrm{spp}$ & $<=2$ & $>=4$ & $<=2$ & $>=4$ \\
\hline
\end{tabular}

The performance for the detection of colistin resistance in gram negative bacteria of different antimicrobial susceptibility testing methods is shown in Table 3. MIKROLATEST MIC colistin showed high sensitivity and specificity; $87.5 \%$ and $90.84 \%$, respectively. The PPVs of VITEK2 system was low; $3.47 \%$ and $9.58 \%$ for the VITEK2 and Mikrolatest MIC colistin, respectively.

Table 3: The performance for the detection of colistin resistance in Enterobacteriaceae of different antimicrobial susceptibility testing methods

\begin{tabular}{|c|c|c|c|c|c|c|c|}
\hline \multirow[t]{2}{*}{ Testing method } & & \multicolumn{2}{|c|}{$\begin{array}{l}\text { BMD no. of } \\
\text { isolates }\end{array}$} & \multirow[t]{2}{*}{$\begin{array}{c}\text { Sensitivity } \\
(\%)\end{array}$} & \multirow[t]{2}{*}{ Specificity (\%) } & \multirow[t]{2}{*}{ PPV (\%) } & \multirow[t]{2}{*}{ NPV (\%) } \\
\hline & & $\mathbf{R}$ & NR & & & & \\
\hline \multirow[t]{2}{*}{ VITEK2 } & $\mathrm{R}$ & 9 & 250 & \multirow{2}{*}{$\begin{array}{l}0.5625 \\
(56.25)\end{array}$} & \multirow{2}{*}{$\begin{array}{l}0.8265 \\
(82.65)\end{array}$} & \multirow{2}{*}{$\begin{array}{c}0.03474 \\
(3.47)\end{array}$} & \multirow{2}{*}{$\begin{array}{l}0.9933 \\
(99.33)\end{array}$} \\
\hline & NR & 8 & $\begin{array}{c}119 \\
1\end{array}$ & & & & \\
\hline \multirow{2}{*}{$\begin{array}{c}\text { Mikrolatest } \\
\text { MIC } \\
\text { colistin }\end{array}$} & $\mathrm{R}$ & $\begin{array}{l}1 \\
4\end{array}$ & 132 & \multirow[t]{2}{*}{$\begin{array}{l}0.875 \\
(87.5)\end{array}$} & \multirow[t]{2}{*}{$\begin{array}{l}0.9084 \\
(90.84)\end{array}$} & \multirow[t]{2}{*}{$\begin{array}{c}0.0958 \\
(9.58)\end{array}$} & \multirow[t]{2}{*}{$\begin{array}{c}0.9984 \\
(99.8)\end{array}$} \\
\hline & NR & 2 & $\begin{array}{c}131 \\
0\end{array}$ & & & & \\
\hline \multirow{3}{*}{$\begin{array}{l}\text { Broth micro } \\
\text { dilution } \\
(\mathrm{BMD})\end{array}$} & $\mathrm{R}$ & 1 & 144 & \multirow[t]{3}{*}{ NA } & \multirow[t]{3}{*}{ NA } & \multirow[t]{3}{*}{ NA } & \multirow[t]{3}{*}{ NA } \\
\hline & & 6 & 2 & & & & \\
\hline & NR & 0 & 0 & & & & \\
\hline
\end{tabular}

$\mathrm{BMD}=$ broth microdilution; $\mathrm{NR}=$ Not resistant $\mathrm{R}=$ resistant. $\mathrm{NA}=$ not applicable: all of the isolates were detected colistin resistance by the Broth micro dilution system in this study; therefore, sensitivity, specificity and NPV were not calculated.

\section{Categorical agreement}

The testing methods were compared to BMD as the reference method. Comparing MICs of BMD with other tests, essential agreement was the lowest for the VITEK2, while the Mikrolatest MIC showed essential agreement greater than $1.5 \%$. VITEK2 showed the lowest categorical agreement $(0.355 \%)$. Most category disagreements were minor errors. There was 1 very major error in the Mikrolatest MIC colistin test (Table4).

Table 4. Agreements of Colistin susceptibility results between different antimicrobial susceptibility testing methods and broth microdilution.

\begin{tabular}{|c|c|c|c|c|c|}
\hline \multirow{2}{*}{ Testing method } & \multicolumn{2}{|c|}{ \% Agreement (no.) } & \multicolumn{3}{c|}{ No. of error } \\
\cline { 2 - 6 } & $\begin{array}{c}\text { Essential } \\
\text { agreement }^{\mathrm{a}}\end{array}$ & $\begin{array}{c}\text { Category } \\
\text { agreement }^{\mathrm{b}}\end{array}$ & $\begin{array}{c}\text { Very Major } \\
\text { error }^{\mathrm{c}}\end{array}$ & $\begin{array}{c}\text { Major } \\
\text { error }^{\mathrm{d}}\end{array}$ & $\begin{array}{c}\text { Minor } \\
\text { error }^{\mathrm{e}}\end{array}$ \\
\hline MIC by Vitek & 0.355 & 0.280 & 0 & 0 & 2 \\
\hline MIC by BMD & 1.49 & 1.21 & NA & 0 & 7 \\
\hline Mikrolatest MIC colistin & 1.50 & 1.24 & 0 & 0 & 6 \\
\hline
\end{tabular}

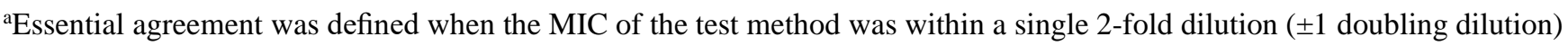
of the reference result.

${ }^{\mathrm{b}}$ Category agreements examines the agreement between sensitive/intermediate/resistant results with the reference method.

${ }^{\mathrm{c}} \mathrm{A}$ very major error happened when the isolate was categorized as susceptible by the test method but resistant by the reference method.

${ }^{\mathrm{d}} \mathrm{A}$ major error occurred when the isolate was categorized as being resistant by the test method but susceptible by the reference method (false-resistant result).

${ }^{\mathrm{e}} \mathrm{A}$ minor error was listed when an isolate was categorized as intermediate by one test method but either susceptible or resistant by another test method.

$\mathrm{NA}=$ Not applicable; there were no susceptible isolates according to the BMD in this study.

\section{Colistin resistant isolates with MIC value}

For isolates with MICs of $4 \mu \mathrm{g} / \mathrm{mL}$ by the Mikrolatest, the resistance rates determined by BMD (MIC $4 \mu \mathrm{g} / \mathrm{mL}$ ) were $12.5 \%$ and $18.7 \%$, respectively. By Mikrolatest test, Colistin MIC was $>16 \mu \mathrm{g} / \mathrm{ml}$ in 8 isolates $(50 \%), 8 \mu \mathrm{g} / \mathrm{ml}$ in 6 isolates $(37.5 \%)$ isolates. Increased MIC value of $>16 \mu \mathrm{g} / \mathrm{ml}$ of $50.00 \%$ of the colistin resistant isolates suggest of high level of resistance in both Mikrolatest and 
BMD tests. No errors and $100 \%$ categorical agreement (for E. coli, $K$. pneumoniae) were observed while comparing colistin susceptibility test results of the Mikrolatest MIC and BMD tests. The difference in proportion of test isolates reported as colistin resistant by the two methods was not found to be statistically significant $(P=0.89)$ (Table 5)

Table 5: Colistin resistant isolates with MIC value

\begin{tabular}{|c|c|c|c|}
\hline MIC Value $\mu \mathrm{g} / \mathrm{ml}$ & Mikrolatest MIC -n (\%) & BMD-n (\%) & \multirow{2}{*}{$0.89^{\text {ns }}$} \\
\hline 4 & $2(12.5)$ & $3(18.7)$ & $5(31.25)$ \\
\cline { 1 - 3 } & $6(37.5)$ & $8(50)$ & \\
\hline$\geq 16$ & $8(50)$ & \\
\hline
\end{tabular}

Chi-square test. ns: not significant.

\section{Comparision of methods:}

The distributions of MICs determined by BMD and Mikrolatest show similar results.

\section{Distribution of colistin resistant Gram-negative bacilli}

Blood (6[37.5\%]) and pus (6[37.5\%] were the most common sources of the isolate, followed by Urine (2 [12.5\%]), and respiratory (2 [12.5\%]). $K$. pneumoniae constituted 8(50\%), E. coli constituted $6(37.5 \%)$ and Enterobacter cloacae constituted $2(12.5 \%)$ of the 16 resistant isolates. No colistin-resistant Pseudomonas isolate was recorded (Table 6).

Table 6: Distribution of colistin resistant Gram -negative bacilli in various clinical samples

\begin{tabular}{|c|c|c|c|}
\hline Specimen & Klebsiella Spp & E. coli & Enterobacter Cloacae \\
\hline Blood & 6 & 0 & 0 \\
\hline Pus & 2 & 4 & 0 \\
\hline Urine & 0 & 0 & 2 \\
\hline BAL & 0 & 2 & 0 \\
\hline Total & 8 & 6 & 2 \\
\hline
\end{tabular}

\section{Antibiotic resistance pattern}

The percentage of antibiotic resistance pattern of all 16 bacterial isolates using Mikrolatest system is shown in [Table 7]. High resistance rates to aminoglycosides, fluoroquinolones, penicillins, $\beta$ lactam/ $\beta$-lactamase inhibitor combinations, cephalosporins, carbapenems and folate pathway inhibitors respectively were observed among all test isolates. Sensitivity of isolates to other drugs tested was shown in Table 7. Ampicillin / Clavulonic acid was sensitive in 2 and 14 were resistant, Piperacillin/Tazobactam was sensitive in 6 and 10 were resistant, Cefuroxime resistant was seen in all 16, Ceftriaxone was sensitive in 2 and 14 were resistant, Cefoperazone/Sulbactam was sensitive in 6 and 10 were resistant, Cefepime was sensitive in 1 and 15 were resistant, Imipenem was sensitive in 6 and 10 were resistant, Meropenem was sensitive in 4 and 12 were resistant, Amikacin was sensitive in 10 and 6 were resistant, Gentamicin was sensitive in 6 and 10 were resistant, Nalidixic Acid was sensitive in 10 and 6 were resistant, Ciprofloxacin was sensitive in 10 and 6 were resistant, Nitrofurantoin was sensitive in 10 and 6 were resistant, Colistin was resistant in all 16, Trimethoprim/Sulfamethoxazole was sensitive in 6 and 10 were resistant, and Tigecycline was sensitive in 4 and 12 were resistant (Table 7).

Table 7: Antimicrobial sensitivity pattern of colistin resistant Gram-negative bacilli

\begin{tabular}{|c|c|c|c|c|}
\hline Antibiotics & Sensitive & Resistant & Sensitive\% & Resistant\% \\
\hline Ampicillin/Clavulonic acid & 2 & 14 & 12.5 & 87.5 \\
\hline Piperacillin/Tazobactam & 6 & 10 & 37.5 & 62.5 \\
\hline Cefuroxime & 0 & 16 & 0 & 100 \\
\hline Ceftriaxone & 2 & 14 & 12.5 & 87.5 \\
\hline Cefoperazone/Sulbactam & 6 & 10 & 37.5 & 62.5 \\
\hline Cefepime & 1 & 14 & 12.5 & 87.5 \\
\hline Imipenem & 6 & 10 & 37.5 & 62.5 \\
\hline Meropenem & 4 & 12 & 25.00 & 75.00 \\
\hline Amikacin & 10 & 6 & 62.5 & 37.5 \\
\hline Gentamicin & 6 & 10 & 37.5 & 62.5 \\
\hline Nalidixic Acid & 10 & 6 & 62.5 & 37.5 \\
\hline Ciprofloxacin & 10 & 6 & 62.5 & 37.5 \\
\hline Nitrofurantoin & 10 & 6 & 62.5 & 37.5 \\
\hline Colistin & 0 & 16 & 0 & 100 \\
\hline Tigecycline & 6 & 10 & 37.5 & 62.5 \\
\hline Trimethoprim/Sulfamethoxazole & 6 & 12 & 25.0 & 75.0 \\
\hline
\end{tabular}


The test results by BMD method by Mikrolatest MIC testi kit are summarized in Figure 1. Two wells in the kit was used as growth control. The Colistin concentration increased in a doubling manner from the wells 'C' to 'G' (0.25 to $16 \mu \mathrm{g} / \mathrm{ml})$. The first well position from the bottom to top showing no growth (granulation, button or turbidity) was considered the MIC value.

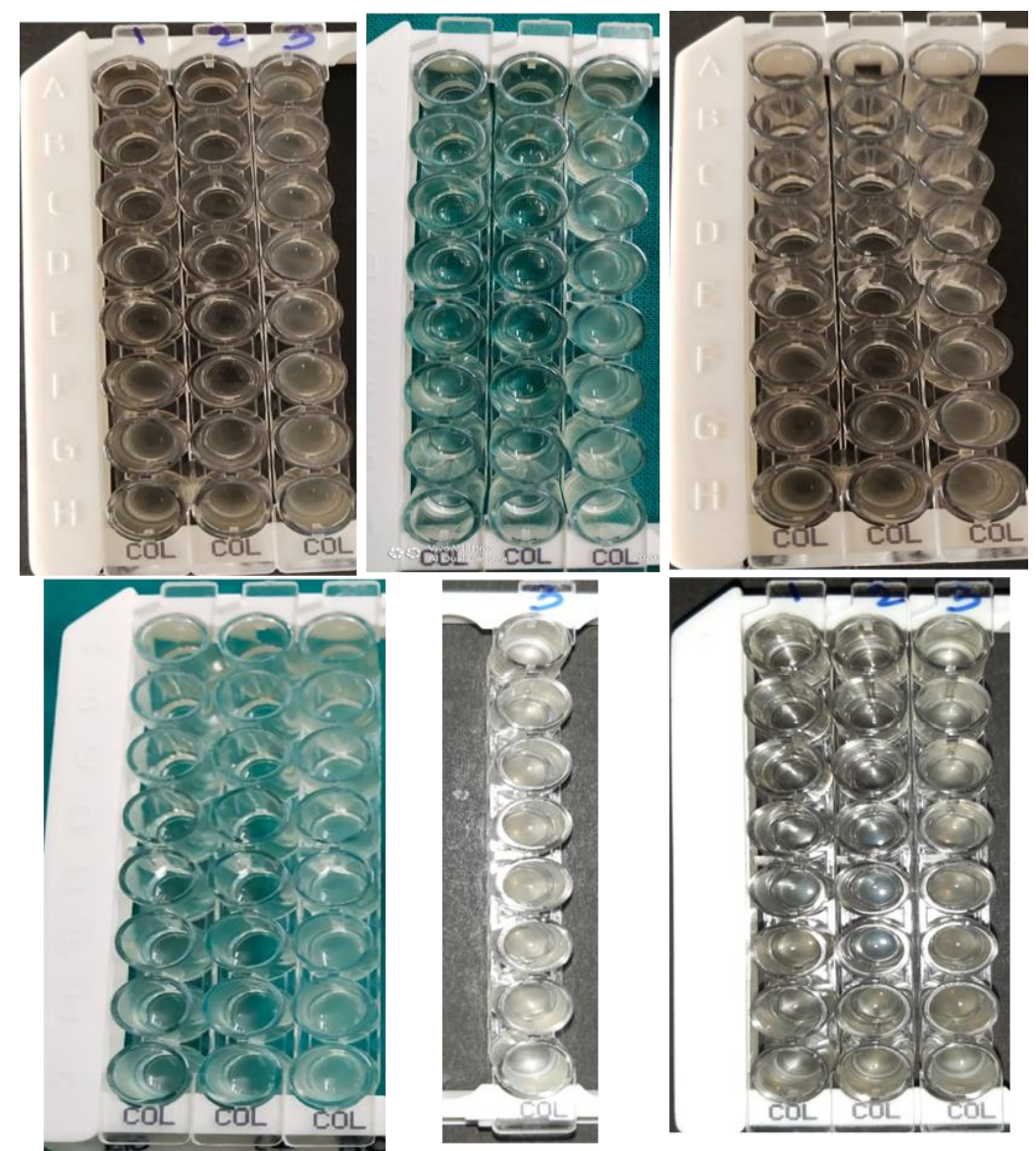

Fig. 1: Colistin susceptibility test results using Mikrolatest minimum inhibitory concentration antibiotic susceptibility testing kit (broth microdilution method)

\section{Outcome of colistin resistant isolates}

The mean age of the patients was 42.5 ( 1 month to $82 \mathrm{yrs})$, six females and ten males, from NICU $(n=1)$, PICU $(n=2)$, ICU $(n=6), \operatorname{OBGY}(n=3)$, $\operatorname{TBCD}(\mathrm{n}=3)$, and MMW $(\mathrm{n}=1)$. The maximum comorbidities present were diabetes, chronic kidney disease (CKD), chronic liver disease, heart disease and chronic obstructive pulmonary disease. Previous hospitalization within 3 months was noted in all 10 patients. Invasive devices were used in all patients.

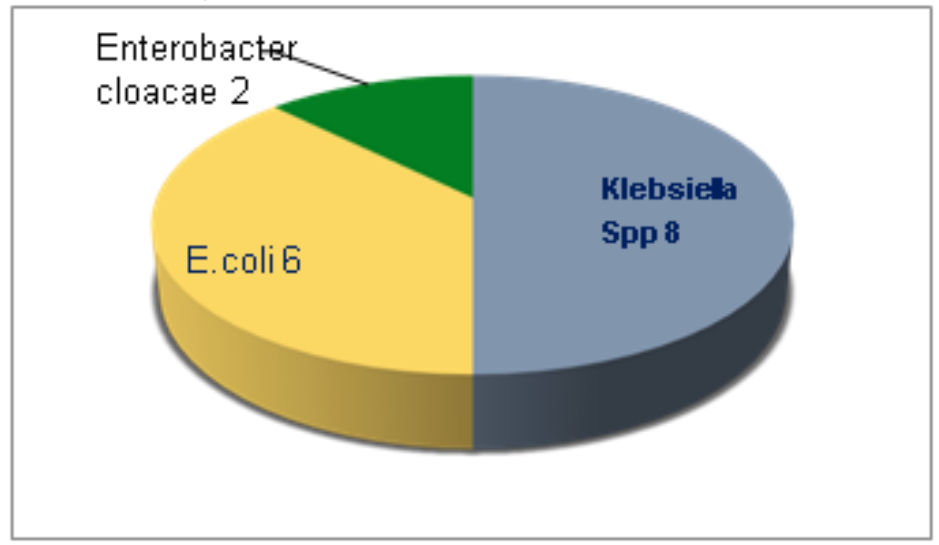

Fig. 2: Species wise distribution of all 16 carbapenem resistant Gram-negative bacterial isolates

\section{Bacterial isolates}

During the study, 16 Colistin-resistant Gram-negative bacteria were isolated from various clinical samples namely blood, urine, pus, pleural fluid and bronchoalveolar lavage respectively, received in microbiology department. Klebsiella spp. was the most common bacterial isolates. Species-wise distribution of all Gram-negative bacterial isolates is shown in [Figure 2]. No discrepancy in bacterial identification results between Mikrolatest and BD was observed. 


\section{DISCUSSION}

Gram-negative bacteria are among the most commonly isolated nosocomial pathogens that are often resistant to fluoroquinolones, aminoglycosides, and beta-lactam antibiotics, including carbapenems and monobactams. This was encouraged colistin usage in the clinical practice as a valid treatment option (10).

In this study, we evaluated the performance of Mikrolatest and Vitek-2 ${ }^{\mathrm{TM}}$ (bioMérieux, MarcyL'Etoile, France) on determination of colistin susceptibility in comparison with gold standard broth microdilution method.

We studied a total of 1458 isolates of the Gramnegative bacteria. The mean age of the patients was 42.5 (1 month to $82 \mathrm{yrs}$ ), six females and ten males, from NICU $(\mathrm{n}=1), \operatorname{PICU}(\mathrm{n}=2), \mathrm{ICU}(\mathrm{n}=6), \mathrm{OBGY}$ $(\mathrm{n}=3)$, TBCD $(\mathrm{n}=3)$, and MMW $(\mathrm{n}=1)$. Singh et al., studied 25 male and nine female patients. The mean age was $45.09 \pm 17.59 \mathrm{yr}$ (17).

In our study, $1.09 \%(\mathrm{n}=16)$ colistin-resistant bacterial isolates were reported in the duration of 12 months. Singh et al., studied 34 carbapenem-resistant bacteria from clinical samples (17).

In our study, Klebsiella pneumoniae constituted $8(50 \%)$, Escherichia coli constituted $6(37.5 \%)$ and Enterobacter cloacae constituted 2 (12.5\%) of the 16 resistant isolates. No colistin-resistant Pseudomonas isolate was recorded; whereas in a study by Singh $e t$ al., revealed that among the 11.8\%(4/34)of test isolates, $100 \%$ (2/2) Acinetobacter junii, $10 \%$ (1/10)of Escherichia coli and $14.3 \%$ (1/7) of Pseudomonas aeruginosa exhibited in vitro colistin resistance by BMD method(17). Majority of reports reveals the resistance rates were below $10 \%$. The variation in resistance rate could be due to usage of different methods (18-20).

In our study, the colistin susceptibility of Escherichia coli (MIC: 8-16 $\mu \mathrm{g} / \mathrm{ml}$ ) and Klebsiella (MIC: 4-16 $\mu \mathrm{g} / \mathrm{ml}$ ) was ascertained (Table 1). Acinetobacter spp. and $\mathrm{P}$. aeruginosa test isolates were classified as colistin susceptible (MIC $\leq 2 \mu \mathrm{g} / \mathrm{ml}$ ) or resistant (MIC $>4 \mu \mathrm{g} / \mathrm{ml}$ ) respectively as per CLSI 2019 guidelines [Table 2]. Colistin susceptibility of E. coli and K. pneumoniae test isolates (MIC $\leq 2$ [sensitive] and $>2$ $\mu \mathrm{g} / \mathrm{ml} \quad$ [resistant]). Study by Singh et al., demonstrates Acinetobacter spp. and Pseudomonas aeruginosa test isolates were classified as colistin susceptible (MIC $\leq 2 \mu \mathrm{g} / \mathrm{ml}$ ) or resistant (MIC $>4$ $\mu \mathrm{g} / \mathrm{ml}$ ) respectively as per CLSI 2019 guidelines. Colistin susceptibility of $E$. coli and $K$. pneumoniae test isolates (MIC $\leq 2$ [sensitive] and $>2 \mu \mathrm{g} / \mathrm{ml}$ [resistant]). Colistin susceptibility of E. coli ATCC 25922 (MIC: $0.25-2 \mu \mathrm{g} / \mathrm{ml}$ ) and Pseudomonas aeruginosa ATCC 27853 (MIC: $0.5-4 \mu \mathrm{g} / \mathrm{ml}$ ) was ascertained using CLSI 2019 guidelines (17).
In our study, MICs of BMD compared with other tests, essential agreement was the lowest for the VITEK2, while the Mikrolatest MIC showed essential agreement greater than $1.5 \%$. VITEK2 showed the lowest categorical agreement $(0.355 \%)$. Most category disagreements were minor errors. The distributions of MICs determined by BMD and Mikrolatest show similar results. No errors and 100\% categorical agreement (for Escherichia coli, Klebsiella pneumoniae) were observed while comparing colistin susceptibility test results of the Mikrolatest MIC and BMD tests. The difference in proportion of test isolates reported as colistin resistant by the two methods was not found to be statistically significant $(\mathrm{P}=0.89)$; whereas a study by Singh et al., revealed two major errors and one very major errors observed during comparision of methods. The difference in proportion of test isolates reported as colistin resistant by the two methods was not found to be statistically significant $(\mathrm{P}=1.000)$ $71.4 \%$ (Acinetobacter baumannii), $85.7 \% \quad(P$. aeruginosa) and $100 \%$ (Acinetobacter junii, Escherichia coli Acinetobacter johnsonii, and Klebsiella pneumoniae). Total three errors (2 major errors for Acinetobacter baumannii and 1 very major errors for Pseudomonas aeruginosa were observed (17).

Marlinghaus et al., evaluated the accuracy of antimicrobial susceptibility test of colistin by using MicroScan Walkaway system. They tested 327 carbapenemase-producing Enterobacteriaceae isolates. Colistin resistant and susceptible noted in 107 and 220 isolates(17,21). Jayol et al., used Manual BMD as the reference method and observed high rate $26.9 \%)$ of major errors with the MicroScan method (22). Pfennigwerth et al., conducted study on 325 carbapenemase producing Enterobacteraceae species, and identified poor performance of MicroScan Walkaway system was observed with 16 MEs and 13 VMEs (23).

In our study, MIKROLATEST MIC colistin showed high sensitivity and specificity; $87.5 \%$ and $90.84 \%$, respectively. The PPVs of VITEK2 system was low; $3.47 \%$ and $9.58 \%$ for the VITEK2 and Mikrolatest MIC colistin, respectively. Mikrolatest showed high sensitivity and specificity and excellent concordance with BMD. VITEK2 test had the lowest sensitivity and the lowest essential and categorical agreement.

In clinical microbiology lab, VITEK 2 and MicroScan were popular for antimicrobial susceptibility. Due to low positive predictive value, these systems may generate nonreliable reports.

In our study setup, the Mikrolatest results were showed MICs and interpretive category results showed relatively good agreement with manual BMD than VITEK2. This may be due to differences in measurement methods of MICs; the Mikrolatest is more similar to BMD than to the VITEK2 (24). 
Therefore, it is a good alternative method for susceptibility tests of colistin. In our study, Mikrolatest showed the best performance among the testing methods. There were no false resistant or false-susceptible results by Mikrolatest. The Mikrolatest showed relatively good agreement with BMD compared to the VITEK2. Most category disagreements were minor errors. Broth microdilution is considered to be gold standard method of colistin susceptibility as compared to VITEK-2 system. Its need of the hour to develop better susceptibility test to avoid therapeutic failures.

\section{CONCLUSION}

Based on the available data, we recommend that dilution-based methods be used for testing whenever parenteral use of the Polymyxin is considered in clinical practice. Colistin resistance $(1.09 \%)$ found in our study is quite alarming. Confirmation of results by Mikrolatest MIC test is recommended for accurate resistance results of colistin. Even though 16 bacterial isolates were tested in our study, the data will be helpful to the clinicians who often faced in treating the MDR (including carbapenem/colistin resistant) Gramnegative bacterial infections with limited treatment options.

\section{CONFLICT OF INTEREST}

Authors declare no conflict of interest.

\section{REFERENCES}

1. Sader, H. S., Farrell, D. J., Flamm, R., Jones, R. N. Antimicrobial susceptibility of Gram-negative organisms isolated from patients hospitalized in intensive care units in United States and European hospitals (2009-2011). Diagn Micr Infec Dis. 2014; 78(4): 443-448.

2. Tan, R., Liu, J., Li, M., Huang, J., Sun, J., Qu, H. Epidemiology and antimicrobial resistance among commonly encountered bacteria associated with infections and colonization in intensive care units in a universityaffiliated hospital in Shanghai. J Microbiol Immunol. 2014; 47(2): 87-94.

3. Eliopoulos, G. M., Cosgrove, S. E., Carmeli, Y.The impact of antimicrobial resistance on health and economic outcomes. Clin Infect Dis, 2003; 36(11): 1433-1437.

4. Lam, S. J., O'Brien-Simpson, N. M., Pantarat, N., Sulistio, A., Wong, E. H., Chen, Y. Y., et al., Combating multidrugresistant Gram-negative bacteria with structurally nanoengineered antimicrobial peptide polymers. Nat. Microbiol. 2016; 1(11): 1-11.

5. Xu, Y., Gu, B., Huang, M., Liu, H., Xu, T., Xia, W., et al., Epidemiology of carbapenem resistant Enterobacteriaceae (CRE) during 2000- 2012 in Asia. J Thorac Dis. 2015; 7(3): 376-385.

6. Perez, F., Van Duin, D. Carbapenem-resistant Enterobacteriaceae: a menace to our most vulnerable patients. Cleve Clin J Med, 2013; 80(4): 225-233.

7. Cantón, R., Akóva, M., Carmeli, Y., Giske, C. G., Glupczynski, Y., Gniadkowski, M., et al., Rapid evolution and spread of carbapenemases among Enterobacteriaceae in Europe. Clin Microbiol Infect, 2012; 18(5): 413-431.

8. Livermore, D. M. Has the era of untreatable infections arrived? J Antimicrob Chemother, 2009;64(suppl_1): i29i36.
9. Falagas, M. E., Kasiakou, S. K., Saravolatz, L. D. Colistin: the revival of polymyxins for the management of multidrugresistant gram-negative bacterial infections. Clin Infect Dis. 2005; 40(9): 1333-1341.

10. Yahav, D., Farbman, L., Leibovici, L., Paul, M. Colistin: new lessons on an old antibiotic. Clin Microbiol Infec. 2012; 18(1): 18-29.

11. Nation, R. L., Li, J. Colistin in the 21st century. Curr Opin Infect Dis. 2009; 22(6): p. 535.

12. Walkty, A., DeCorby, M., Nichol, K., Karlowsky, J. A., Hoban, D. J., Zhanel, G. G. In vitro activity of colistin (polymyxin E) against 3,480 isolates of Gram- negative bacilli obtained from patients in Canadian hospitals in the CANWARD study, 2007- 2008. Antimicrob Agents Chemother. 2009; 53(11): 4924-4926.

13. Patel, J. B., Cockerill, F. R., Bradford, P. A. Performance standards for antimicrobial susceptibility testing: twentyfifth informational supplement. 2015. Clinical and Laboratory Standards Institute. 2015; 35(3): 29-50.

14. Lee, M., Chung, H. S. Different antimicrobial susceptibility testing methods to detect ertapenem resistance in Enterobacteriaceae: VITEK2, MicroScan, Etest, disk diffusion, and broth microdilution. J. Microbiol. Methods. 2015; 112: 87-91.

15. Juyal, D., Thawani, V., Thaledi, S., Dhawan, B. Polymyxin Nordmann/Poirel test for rapid detection of polymyxin resistance in Enterobacteriaceae: Indian experience. Indian J. Med. Microbiol. 2016; 34(4): 564.

16. Lai, C. C., Chen, Y. S., Lee, N. Y., Tang, H. J., Lee, S. S. J., Lin, C. F., et al., Susceptibility rates of clinically important bacteria collected from intensive care units against colistin, carbapenems, and other comparative agents: Results from Surveillance of Multicenter Antimicrobial Resistance in Taiwan (SMART). Infect Drug Resist. 2019; 12: 627.

17. Singh, R. I., Bhatia, M., Anusha, K. R., Singh, V., Omar, B. J., Gupta, P. Comparative evaluation of microscan walkaway 96 plus ID/AST system and mikrolatest broth microdilution kit in assessing In vitro colistin susceptibility of carbapenem-resistant clinical gram-negative bacterial isolates: Experience from a tertiary care teaching hospital in Rishikesh, Uttarakhand. Indian J. Med. Microbiol. 2019; 37(4): 502 .

18. Falagas, M. E., Rafailidis, P.I., Matthaiou, D.K. Resistance to polymyxins: mechanisms, frequency and treatment options. Drug Resist Update. 2010. 13(4-5): 132-138.

19. Li, J., Rayner, C. R., Nation, R. L., Owen, R. J., Spelman, D., Tan, K. E., et al., Heteroresistance to colistin in multidrug-resistant Acinetobacter baumannii. Antimicrob. Agents Chemother. 2006; 50(9): 2946-2950.

20. Hawley, J. S., Murray, C. K., Jorgensen, J. H. Colistin heteroresistance in Acinetobacter and its association with previous colistin therapy. A Antimicrob. Agents Chemother. 2008; 52(1): 351-352.

21. Schäfer, E., Malecki, M., Tellez - Castillo, C. J., Pfennigwerth, N., Marlinghaus, L., Higgins, P. G., et al., Molecular surveillance of carbapenemase-producing Pseudomonas aeruginosa at three medical centres in Cologne, Germany. Antimicrob Resist In. 2019; 8(1): 1-7.

22. Jayol, A., Nordmann, P., André, C., Poirel, L., Dubois, V. Evaluation of three broth microdilution systems to determine colistin susceptibility of Gram-negative bacilli. J Antimicrob Chemother. 2018; 73(5): 1272-1278.

23. Pfennigwerth, N., Kaminski, A., Korte-Berwanger, M., Pfeifer, Y., Simon, M., Werner, G., et al., Evaluation of six commercial products for colistin susceptibility testing in Enterobacterales. Clin Micro Inf. 2019. 25(11): 1385-1389.

24. Garcia, L. S. ed., Clinical microbiology procedures handbook. American Society for Microbiology Press. 2010: 2 . 